\title{
AN ELECTROPHORETIC INVESTIGATION ON THE PROPERTIES OF THE HEXAVALENT PLUTONIUM IONS IN ULTRADILUTED AQUEOUS SOLUTIONS
}

\author{
Bontchev G. \\ Department of Chemistry, Medical University "Prof. P. Stoyanov" - Varna \\ Reviewed by: Assoc. Prof. N. Hadjiiski
}

\begin{abstract}
Investigation on the chemistry of transuranic elements is an extremely complex task. None of these elements are stable, they decay radioactively and are not available in large amounts. Heavy transuranic elements are difficult and expensive to produce, and their prices go up rapidly with atomic number. As of 2008, weapons-grade Plutonium cost around \$4,000/gram, and Californium cost $\mathbf{\$ 6 0 , 0 0 0 , 0 0 0 / g r a m}$. Moreover, working even with microgram quantities of these chemicals contains a substantial health risk due to their radioactivity and toxicity. However, using the method of radioactive indicators as well as appropriate instruments it is possible to study transuranic ions behavior in water solutions at sub-microconcentration levels as low as $10^{-8}$ $10^{-10} \mathrm{mol.l}^{-1}$. In this paper the highly suitable electromigration technique is discussed and applied to examine some hexavalent Plutonium properties. A set of collected radioanalytical data, including values of parameters such as ion mobilities, molar volumes, Stocks radii, hydration numbers, diffusion coefficients as well as their temperature dependence in aqueous solutions is presented.
\end{abstract}

Key words: Pu-237, hexavalent plutonium, electrophoresis, electromigration

\section{INTRODUCTION}

There are not many sources of relevant plutonium characteristics. Due to Plutonium use mainly for military purposes, the majority of profound investigations represent a classified information and are not available to the public. The isotope $\mathrm{Pu}-239$ is a key fissile component in nuclear weapons, due to its ease of fission and availability.

The isotope Pu-238 has a half-life of 87.5 years; it emits a large amount of thermal energy with low levels of both gamma rays and spontaneous neutron particles. Being an alpha emitter, it combines high energy radiation with low penetration and thereby requires minimal shielding. One kilogram of the isotope can generate 22 million kilowatt-hours of heat energy (18). These characteristics make it well-suited for electrical power generation for devices which must function without direct maintenance for timescales approximating a human lifetime. It is therefore used in radioisotope thermoelectric generators and radioisotope heater units such as those in the Cassini, Voyager and New Horizons space probes (17). Due to its high toxicity, medical application is limited, although it has been used

\footnotetext{
Address for correspondence:

G. Bontchev, Dept. of Chemistry, Medical University "Prof. P. Stoyanov" - Varna, 55 Marin Drinov Str., BG-9002, Varna, Bulgaria

e-mail: bontchev@mu-varna.bg
}

successfully to power artificial heart pacemakers, to reduce the risk of repeated surgery $(19,23)$.

Isotopes and compounds of Plutonium are extremely toxic due to their radioactivity, however, based on chemical toxicity alone, the element is less dangerous than arsenic or cyanide (16). Plutonium is more dangerous when inhaled than ingested. The risk of lung cancer increases once the total dose equivalent of inhaled radiation exceeds $400 \mathrm{mSv}$ (15). When Plutonium is absorbed into the body, it is excreted very slowly, with a biological half-life of 200 years. The alpha radiation Plutonium emits does not penetrate the skin, but can irradiate internal organs when plutonium is inhaled or ingested (17). Particularly at risk is the skeleton, where it is likely to be absorbed by the bone surface, and the liver, where it collects and becomes concentrated (21). Considerably larger amounts may cause acute radiation poisoning and death if ingested or inhaled; however, no human is known to have died because of inhaling or ingesting Plutonium. Investigations on properties of Plutonium species at microconcentrations levels should be made by appropriate techniques regarding the well-known fact, that there are serious differences in behavior of radioisotope in trace, $\mu \mathrm{M}$ and $\mathrm{mM}$ amounts. The specific features of microconcentrated radioactive solutions are being usually connected to formation of pseudocolloids as well as polymer associates $(6,10,11)$. Thus, electrochemical methods as electrophoresis, electromigration, transference numbers and potentiometric analysis are extremely suitable, offering 
a tracer working concentrations down to $10^{-10}-10^{-11} \mathrm{M}$. Moreover, these methods guarantee a unique, direct measurement of basic thermodynamic parameters, such as ion velocity, diffusion and electrodiffusion rates (4). Most reliable results can be retrieved by the method of horizontal zone electrophoresis in free electrolyte systems, by which a major part of side effects (electroosmosis, rheophoresis, phase equilibrium etc.) are avoided (2).

\section{MATERIALS AND METHODS}

Experimental part of this work was done at the Joint Institute for Nuclear Research (JINR) - Dubna, Russia, in the Flerov Laboratory of Nuclear Reactions (FLNR) and Djelepov Laboratory of Nuclear Problems (DLNP).

The aqueous chemistry of hexavalent plutonium in nanogram amounts was studied using the method of horizontal zone electrophoresis in a free electrolyte. All the experiments were performed with ${ }^{237} \mathrm{Pu}, \mathrm{T} 1 / 2=45,6 \mathrm{~d}$; EC (99\%), $\alpha(0,033 \%)$, the energy of its main $\gamma$-rays is $\mathrm{E}_{\gamma}=97,1$ $\mathrm{keV}(12,5 \%), 101,1 \mathrm{keV}(20,1 \%), 113,9 \mathrm{keV}(7,6 \%)(22)$. This isotope is a gamma-tracer and meets the radiochemical requirements for studies on the aqueous chemistry of plutonium in ultra low concentrations. The Plutonium-237 was produced via ${ }^{235} \mathrm{U}(\alpha, 2 \mathrm{n}){ }^{237} \mathrm{Pu}$ reaction on the U-200 cyclotron (FLNR, JINR). After radiochemical purification, $\mathrm{PuO}_{2}\left(\mathrm{NO}_{3}\right)_{2}$ with high specific activity was obtained. The plutonium was stabilized in a hexavalent state in the presence of $\mathrm{KBrO}_{3}$. In each experiment a volume of $5 \mu \mathrm{l}(100$ $\mathrm{kBq})$ of ${ }^{237} \mathrm{Pu}$ was injected into the electrophoretic cell. The formed active zone of ${ }^{237} \mathrm{Pu}(\mathrm{VI})$ was moved under the influence of constant electric field gradient, which was 2-10 V.cm ${ }^{-1}$ in different electrophoretic runs. The electrophoretic cell was continuously scanned by means of a CsI(Tl) detector of a completely automated electrophoresis device (7). Collected experimental data were mathematically processed using numerical methods by means of specialized software - Equilibrium (1) and Microcal ${ }^{\mathrm{TM}} \operatorname{Origin}^{\circledR}(20)$.

\section{RESULTS AND DISCUSSION}

A cycle of well-planned electrophoretic experiments was done. In each separate experiment four specific radioactive zone parameters are traced: direction of movement, form, width and velocity. Direction of movement reveals the sign of a ions charge; geometrical parameters and their stability shows the presence or absence of side interactions (adsorption, hydrolysis and pseudocolloid formation); velocity itself appears to be the base quantitative electrochemical characteristic of the ion being investigated. By the help of the existing electromigration methodic (2) ion velocity can be used to derive information about important physico-chemical ion characteristics, such as ion mobility, relative ion conductance, Stocks radius, molar volume, hydration number as well as diffusion coefficient into particular experimental conditions.

\section{Determining the Plutonium (VI) ion mobility}

In each experiment, after injection of the radionuclide the electric field has been switched on, which results to electrophoretic traveling of the zone. Periodically, the position of the zone (here: the maximum zone activity) has been determined, tracing in such a way its movement along the tube. Since the ions in uniform electric field migrate with a constant velocity, there should be a linear correlation between the time and position of the zone. Results can be used to find out the ion velocity, and, consequentially, ion mobility. All experiments were done using a nitrate medium $(0,1 \mathrm{M}$ $\mathrm{HNO}_{3}$ ). Conditions were as follows: ionic strength $\mu=0,1000$ mol. $1^{-1}$, gradient of the electric field $\Delta \mathrm{E}=8,03$ $\mathrm{V} . \mathrm{cm}^{-1}$. The only difference between separate experiments were the temperature of the electrolyte system, fact, which will be used later to determine some parameters' temperature dependence. Obtained results are shown in Table 1.

Table 1. Plutonium (VI) absolute ion velocity and ion mobility measured in 0,1 $\mathrm{M} \mathrm{HNO}_{3}$ at different temperatures.

\begin{tabular}{||c|c|c|c||}
\hline Experiment & $\begin{array}{c}\text { Temperature, } \\
{ }^{\circ} \mathrm{C}\end{array}$ & $\begin{array}{c}\text { Absolute ion } \\
\text { velocity, } \mathrm{cm}^{-1} \mathrm{~s}^{-1}\end{array}$ & $\begin{array}{c}\text { Ion mobility } \\
\mathrm{cm}^{2} . V-1 . \mathrm{s}^{-1}\end{array}$ \\
\hline 1 & 20,3 & $(4,04 \pm 0,02) \cdot 10^{-3}$ & $(5,03 \pm 0,02) \cdot 10^{-4}$ \\
\hline 2 & 30,0 & $(4,73 \pm 0,02) \cdot 10^{-3}$ & $(5,89 \pm 0,02) \cdot 10^{-4}$ \\
\hline
\end{tabular}

It has been detected that Plutonium zone migrates to the cathode showing a strictly constant speed and keeping its initial narrow, regular Gauss-shaped form. Hence, one can conclude that the zone consists of positive hydrated ions which were not engaged in side processes as hydrolysis and adsorption to the inner cell's surface, therefore the values obtained should be an adequate ones. Reference data for comparison could not be found, but ion mobility of other hydrated cations in the very same condition may be cited, for example, ion mobility of $\operatorname{In}_{\mathrm{aq}}{ }^{3+}$ at $20,0{ }^{\circ} \mathrm{C}$ is shown to be $(4,46 \pm 0,01) \cdot 10^{-4} \mathrm{~cm}^{2} \cdot \mathrm{V}^{-1} \cdot \mathrm{s}^{-1}(2)$. This slightly lower value for a ion with higher charge reveals that form $\mathrm{PuO}_{2 \text { (aq.) }}{ }^{2+}$ should possess poor hydration affinity.

Ion mobility, measured in the electrolyte solutions with a different ionic strength, shows different values, which is in agreement to the Onzager's limiting low (4):

$$
\mathbf{u}=\mathbf{u}_{0}-\mathbf{A} \cdot \mu^{1 / 2}
$$

where $\mathbf{u}$ - ion mobility, $\mathrm{cm}^{2} \cdot \mathrm{V}^{-1} \cdot \mathrm{s}^{-1}, \mathbf{u}_{0}$ - ion mobility at infinite dilution, $\mathrm{cm}^{2} . \mathrm{V}^{-1} \cdot \mathrm{s}^{-1}, \mu$ - ionic strength, mol. $1^{-1}, \mathbf{A}$ - an empiric factor $\left(\mathrm{A} \approx 5,5 \pm 0,05\right.$ for cations $\left.\mathrm{Me}^{2+/ 3+}(14)\right)$. Applying this equation toward the found results we obtain for the $\mathrm{Pu}(\mathrm{VI})$ ion mobility at infinite dilution following values:

at $20,3{ }^{\circ} \mathrm{C}:(6,77 \pm 0,05) \cdot 10^{-4} \mathrm{~cm}^{2} \cdot \mathrm{V}^{-1} \cdot \mathrm{s}^{-1}$ and at $30,0{ }^{\circ} \mathrm{C}:(7,63 \pm 0,05) \cdot 10^{-4} \mathrm{~cm}^{2} \cdot \mathrm{V}^{-1} \cdot \mathrm{s}^{-1}$, 
which is in accordance to the reference data: $\mathbf{u}_{0}\left(\mathrm{Ba}^{2+}\right)$ $=5,7 \cdot 10^{4} \quad \mathrm{~cm}^{2} \cdot \mathrm{V}^{-1} \cdot \mathrm{s}^{-1}, \quad \mathbf{u}_{0}\left(\mathrm{Ra}^{2+}\right)=6,0.10^{-4} \quad \mathrm{~cm}^{2} \cdot \mathrm{V}^{-1} \cdot \mathrm{s}^{-1}$, $\mathbf{u}_{0}\left(\mathrm{~Pb}^{2+}\right)=7,0.10^{-4} \mathrm{~cm}^{2} \cdot \mathrm{V}^{-1} \cdot \mathrm{s}^{-1}(3)$. These data can be used to predict Plutonium (VI) ion mobility (and all related parameters) in variety of electrolyte systems.

\section{Determining the Plutonium (VI) temperature coefficient}

Ion mobility (and all related parameters) grows as temperature increase by the factor of nearly $2 \%$ per degree (9). More strictly, the relation between ion mobility and temperature $(T, K)$ can be given as (13):

$$
\mathbf{u}\left(\mathbf{T}_{2}\right)=\mathbf{u}\left(\mathbf{T}_{1}\right)\left[\mathbf{1}+\alpha\left(\mathbf{T}_{2}-\mathbf{T}_{1}\right)\right],
$$

where $\alpha$ - temperature coefficient of first order, $\mathrm{deg}^{-1}$. As we have ion mobility of $\mathrm{PuO}_{2 \text { (aq.) }}{ }^{2+}$ already determined at two different temperatures, calculation of temperature coefficient for this hydrated ion could now be done:

$$
\alpha=0,0176 \text {, }
$$

and its value is very close to the expected one, as it has been mentioned above. This exact value can be used to predict Plutonyl ion mobility (and all related parameters) in close temperature range $0-50{ }^{\circ} \mathrm{C}$.

\section{Determining the Plutonium (VI) equivalent conductance}

One of the most conventional electrochemical parameter is ion equivalent conductance $1, \mathrm{~m}^{2} \cdot \Omega^{-1}$. $\mathrm{mol}^{-1}$. Its value is often used as a result of routine electrophoretic analysis and plays a major role in physico-chemical investigations. There is a simple relation between $\lambda$ and ion mobility $\mathbf{u}(9)$ :

$$
\lambda=\mathbf{F} . \mathbf{u} \text {, }
$$

where $\mathbf{F}=96485{\mathrm{C} . \mathrm{mol}^{-1}}^{-1}$ is a Faraday constant. According to this equation we have calculated values of $\mathrm{PuO}_{2(\text { aq. }}{ }^{2+}$ equivalent conductance to be as follows:

$$
\begin{aligned}
& \text { at } 20,3{ }^{\circ} \mathrm{C}:(4,85 \pm 0,02) \cdot 10-3 \mathrm{~m}^{2} \cdot \Omega^{-1} \cdot \mathrm{mol}^{-1} \text { and } \\
& \text { at } 30,0{ }^{\circ} \mathrm{C}:(5,68 \pm 0,02) \cdot 10-3 \mathrm{~m}^{2} \cdot \Omega^{-1} \cdot \mathrm{mol}^{-1}
\end{aligned}
$$

Extrapolation to ionic strength zero leads to equivalent conductance at infinite dilution $\lambda_{0}$ (usually measured near $20^{\circ} \mathrm{C}$ ) values as follows:

at $20,3{ }^{\circ} \mathrm{C}:(6,53 \pm 0,02) \cdot 10^{-3} \mathrm{~m}^{2} \cdot \Omega^{-1} \cdot \mathrm{mol}^{-1}$.

Comparison with the reference data $6,20 \cdot 10^{-3} \mathrm{~m}^{2} \cdot \Omega^{-1} \cdot \mathrm{mol}^{-1}$ for $\mathrm{Sr}^{2+}$ and $6,60 \mathrm{~m}^{2} \cdot \Omega^{-1} \cdot \mathrm{mol}^{-1}$ for $\mathrm{Ba}^{2+}(5)$ shows an extremely good rate of agreement. Knowing the value of temperature coefficient for the hydrated Plutonium (VI) ion, one can easily do estimations for temperatures, others than $20,3{ }^{\circ} \mathrm{C}$.

\section{Determining the Plutonium (VI) Stocks radius}

The Stocks radius $\mathbf{r}_{\mathbf{s}}$ of ions gave us extremely useful information about the state of the ion in dissolute form and can be used for characterization of its hydration shell (8). Although attention should be drawn to the fact, that the electrotransport methods are practically unique in describ- ing kinetically stabile ion formations (4). For calculation of the Stocks radii the Stocks relation can be used (9):

$$
\mathbf{r}_{\mathrm{s}}=\mathbf{Z e} /(\mathbf{6} \pi \eta \mathbf{u})
$$

where $\mathbf{Z}$ is the absolute charge of the ion, $\mathbf{e}=1,602 \cdot 10^{-19} \mathrm{C}$ is electron charge, $\eta$ is the dynamic viscosity of solution (for a dilute water systems at $20^{\circ} \mathrm{C} \pi \approx 0,001004$ Pa.s). Having values of Plutonium (VI) ions mobility determined, we have calculated Stocks radius for the $\mathrm{PuO}_{2 \text { (aq.) }}{ }^{2+}$ ion as follows:

at $20,3{ }^{\circ} \mathrm{C}: 3,4 \pm 0,1 \AA$.

Extrapolation to ionic strength zero leads to the following $\mathrm{r}_{\mathrm{s}}^{0}$ value:

at $20,3{ }^{\circ} \mathrm{C}: 2,5 \pm 0,1 \AA$.

However, all this values should be corrected, as it is known that Stocks relation (4) looses its linearity beneath approximately $4 \AA$ (12). The correction method is also described in reference cited. Finally, we have obtain followed values for $\mathrm{PuO}_{2(\text { aq.) }}{ }^{2+}$ at $20,3{ }^{\circ} \mathrm{C}$ :

$$
\begin{aligned}
& r_{s}=4,2 \pm 0,1 \AA \text { and } \\
& r_{s}^{0}=3,8 \pm 0,1 \AA .
\end{aligned}
$$

Reference value for comparison $\mathrm{r}_{\mathrm{s}}{ }^{0}\left(\mathrm{Zn}_{\mathrm{aq}}{ }^{2 \dagger}\right)=4,4 \AA$ (12) shows an excellent agreement with our data.

\section{Determining the Plutonium (VI) absolute and molar volumes}

The absolute ion volume $\mathbf{V}_{\mathbf{s}}$ as well as the molar ion volume $\mathbf{V}_{\mathbf{s}}^{\mathbf{0}}$ are important parameters, significant for the solutions' structure investigation. They could be connected to the Stocks radius rs by the following equations (4):

$$
\begin{aligned}
& \mathbf{V}_{\mathbf{s}}=4 / 3 \cdot \pi \mathbf{k} \mathbf{r}_{\mathbf{s}}{ }^{3} \\
& \mathbf{V}_{\mathbf{s}}{ }^{0}=4 / 3 \cdot \mathrm{N}_{\mathrm{A}} \pi \mathbf{k r}_{\mathbf{s}}{ }^{3},
\end{aligned}
$$

where $=6,022.10^{23} \mathrm{~mol}^{-1}$ is the Avogadro constant and $\mathbf{k}$ packaging factor (for a simple hydrated ions $\mathbf{k}=1$ ). Using the value obtained for the $\mathrm{PuO}_{2 \text { (aq.) }}{ }^{2+}$ Stocks radius we have calculated absolute volume and molar volume of the hydrated Plutonium (VI) ion, respectively, as follows:

$$
\begin{aligned}
& \mathbf{V}_{\mathbf{s}} \approx 310 \AA^{3} \text { and } \\
& \mathbf{V}_{\mathbf{s}}^{\mathbf{0}} \approx 1,9 \cdot 10^{26} \AA^{3} \cdot \mathrm{mol}^{-1} .
\end{aligned}
$$

Reference data for comparison shows the absolute volume of the $\mathrm{Zn}_{\mathrm{aq}}{ }^{2+}$ equal to $360 \AA^{3}(12)$.

\section{Determining the Plutonium (VI) hydration number}

Comparing the Stocks rs and the crystallographic $\mathbf{r}_{\mathbf{k}}$ radii of the given ion one can estimate the ion hydration number nsthe mean amount of water molecules, coordinated to the solvated ion. Described estimation could be done by the following equation (4):

$$
\mathbf{n}_{\mathbf{s}}=4 / 3 \cdot \pi\left(\mathbf{r}_{\mathrm{s}}^{3}-\mathbf{r}_{\mathbf{k}}{ }^{3}\right) / \mathbf{V}_{\mathrm{L}},
$$


where $\mathbf{V}_{\mathbf{L}}$ is the solvent's molecule volume (for the water corresponding value is approximately $30 \AA^{3}$ ). Crystallographic radius for $\mathrm{PuO}_{2 \text { (aq.) }}{ }^{2+}$ is unknown, so here we can use $r_{s}^{0}$ instead. Hence, the value of the hydration number of Plutonium (VI) into the investigated solutions we have found to be 2-3. For comparison, hydration number for the $\mathrm{Zn}^{2+}$ in diluted aqueous systems has been reported to be approximately 12 (12). Relatively small value of $\mathrm{PuO}_{2 \text { (aq.) }}{ }^{2+}$ hydration number clearly proves the expected tendency for Plutonyl ions to suffer very light hydration.

\section{Determining the Plutonium (VI) diffusion coefficient}

The most important kinematical ion parameter appears to be its coefficient of diffusion. Though there is developed techniques for its measurement, most of them are complicated, need a long experimental cycles and are applicable for the specialized aims only. However, it is possible to find out an estimation of the diffusion coefficient, using the Nernst-Einstein low, which gives a connection between micro-kinematical properties of the ion (such as ion mobility) and its macro-features (diffusion coefficient) (9):

$$
\mathbf{D}=\mathbf{u R T} / \mathbf{Z F},
$$

where $\mathbf{D}$ is the coefficient of diffusion, $\mathrm{cm}^{2} \cdot \mathrm{s}^{-1}, \mathbf{T}$ - temperature, $\mathrm{K}$, and $\mathbf{R}=8,314 \mathrm{~J} \cdot \mathrm{mol}^{-1} \cdot \mathrm{K}^{-1}$ is the universal gas constant. Strictly, the Nernst-Einstein low is obeyed in infinitely diluted solutions only; nevertheless an accuracy of $10-15 \%$ is often achieved for real solutions (9).

Using the Nernst-Einstein low we have found the diffusion coefficient $D$ and the diffusion coefficient at infinite dilution $\mathbf{D}^{\mathbf{0}}$ for the $\mathrm{PuO}_{2 \text { (аq) }}{ }^{2+}$ in the investigated solutions to be as follows:

$\mathrm{D}=6,4 \cdot 10^{-6} \mathrm{~cm}^{2} \cdot \mathrm{s}^{-1}$ and

$\mathrm{D}^{0}=8,6 \cdot 10^{-6} \mathrm{~cm}^{2} \cdot \mathrm{s}^{-1}$.

Unfortunately, there are no reference data for comparison available, however, the found result seems to be a reasonable one, taking into account that values of simple cations' diffusion coefficients in diluted aqueous solutions can usually be found within the range of $2^{-10} \cdot 10^{-6} \mathrm{~cm}^{2} \cdot \mathrm{s}^{-1}(2)$.

\section{CONCLUSION}

In order to understand the specific chemical behavior of Plutonium (VI) species in diluted aqueous solution, a set of electrochemical experiments were carried out. A highly suitable device for a horizontal zone electrophoresis in a free electrolyte systems as well as an existing methodic for the electrochemical analysis were used. As a result, the most important physico-chemical properties of the hydrated $\mathrm{Pu}(\mathrm{VI})$ ions have been determined by significant accuracy. It has been shown, that in ultradiluted ( $\mu \mathrm{M}$ range) water solutions $\mathrm{PuO}_{2 \text { (aq.) }}{ }^{2+}$ reports to be a small, lightly hydrated cation with a thin solvate shell.

\section{REFERENCES}

1. Áî í ‘åâ, Ã., Áî æè êîâ, Ã., È âàî îâ, Ï . è äd.

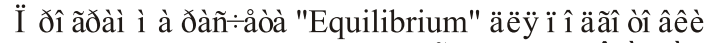

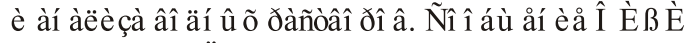
Đ12-2003-75, Äóáí à, 2003

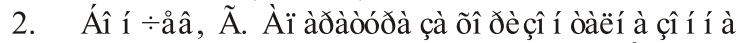

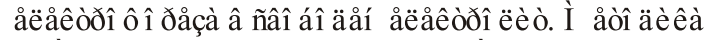

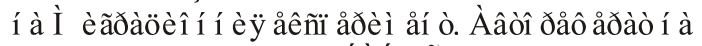
äî êôi đonêà äèñåđòàòèy, ÁÁí , Ñî ồ̀y, 2003

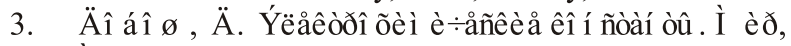
İ î ñêàà, 1980

4. Êđåñôîâ, Ã., Í î âĩ ñåêî â, Í ., Ï ådåëû ãèí È.

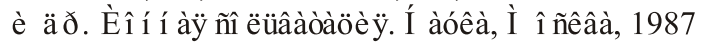

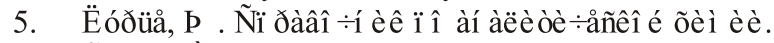
Õè̀ èỳ, İ î ñêâà, 1989

6. Í åñì åÿí î â, À. Đäàè õ òè èỳ. Õèì èÿ, İ înêâà, 1978

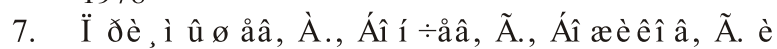

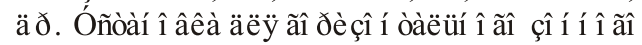

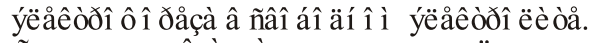
Ñî î áù åí èå Î Èß È Đ13-2000-43, Äóái à, 2000

8. Đî áèí ñ̂̀ í, Đ., Ñòî êñ, Đ. Đànoôâîu đû ýe̊âêòî ëèòî â. Ėçä. èí î ñòd. ëèò., İ î ñêâà, 1963

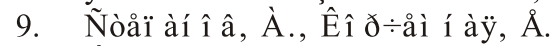

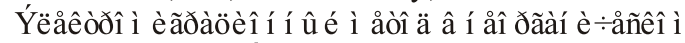
ài àèèça. Õèi èy̆, İ î ñêâà, 1979

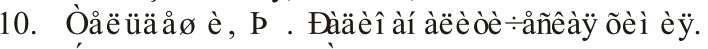
Ýí ådãi àồi ì èçäàò, İ î neêàà, 1987

11. Ôđèäëàí äåð, Ã., Êåí åäè, Ä., İ èëúð, Ä.

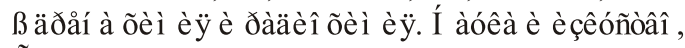
Ñ̂̀ ồ è, 1970

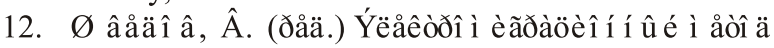

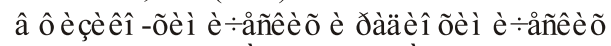
èñ̃ẽåäâi âà èỹõ. Àoôi ì èçäàò, İ î ñêầ, 1971

13. Ýðäåé-Ãðóç, Ò. Bâeåá èy ï i̊o̊åi înà â âî äí û õ

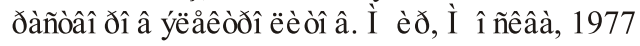

14. Bontchev, G., Bojikov, G., Ivanov, P. Tm-167: an electrophoretic investigation on the properties in the ultradiluted aqueous solutions. Scripta Scientifica Medica, Medical University - Varna, 36, 2004, pp. 21-24

15. Brown, S.C., Schonbeck M.F., McClure D. et al. Lung cancer and internal lung doses among plutonium workers at the Rocky Flats Plant: a case-control study. American Journal of Epidemiology (Oxford Journals), 160, Vol. 2, 2004, pp. 163-172.

16. Cohen, B.L., Ott, K.O., Spinrad, B.I. (eds.) Nuclear Energy. New York (NY): Plenum Press, 1985, pp. 355-365

17. Emsley, J. "Plutonium". Nature's Building Blocks: An A-Z Guide to the Elements. Oxford (UK): Oxford University Press, 2001, pp. 324-329

18. Heiserman, D.L. "Element 94: Plutonium". Exploring Chemical Elements and their Compounds. New York (NY): TAB Books, 1992, pp. 337-340

19. Kolb W., Frame, P. Living With Radiation: the First Hundred Years, Third Ed. Syntec Inc., 2002

20. Microcal ${ }^{\mathrm{TM}}$ Origin ${ }^{\circledR}$, Ver. 6.0, Microcal Software, Inc. Northampton USA. Copyright (C) 1991-1999 (http://www.microcal.com)

21. Miner, W.N., Schonfeld, F.W. "Plutonium". The Encyclopedia of the Chemical Elements. New York 
Bontchev G.

(NY), Reinhold Book Corporation, 1968, pp.

540-546.

22. National Nuclear Data Center, Brookhaven National Laboratory. Nuclear Data Sheets

(http://www.nndc.bnl.gov)
23. Venkateswara, S.M., Ilankumaran V., Srinivasa N.R. Trends in Cardiac Pacemaker Batteries. Indian Pacing Electrophysiol., 4, Vol. 4, 2004, pp. 201-212. 